literature information in Japan, was used in about a half of Japanese CPGs.

Implications for Guideline Developers/Users It is necessary for further study to clarify what sources of information should be used for development of trustworthy CPGs.

\section{P342 ASSESSMENT OF THE RECOMMENDATIONS STRUCTURE IN EIGHT CLINICAL PRACTICE GUIDELINES DEVELOPED IN COLOMBIA}

1,2 1 Florez, ${ }^{1} \mathrm{~A}$ Perez, ${ }^{1} \mathrm{~L}$ Prieto, ${ }^{1} \mathrm{~L}$ Cañon. ${ }^{1}$ Instituto de Evaluación Tecnológica en SaludIETS, Bogota, Colombia; ${ }^{2}$ Universidad de Antioquia, Medellin, Colombia

\section{0:1136/bmjqs-2013-002293.263}

Background There is not enough information to guide editorial wording of recommendations within CPG (Clinical Practice Guidelines) development. The AGREE-II instrument suggests the inclusion of population, intervention and outcome (P-I-O) components within recommendations.

Objective To evaluate P-I-O component in CPG recommendations and to analyse its relationship with the AGREE-II evaluation.

Methods Eight recently developed in Colombia CPG were chosen and assessed by four methodological experts; the presence of P-I-O component in each recommendation was established, and compared with an external evaluation score of the 15th item of AGREE-II instrument.

Results Eight guidelines with a total of 691 recommendations were evaluated, all of them were appraised by external international review with the Spanish AGREE-II instrument and its use were recommended. An average of $9.9 \%$ of recommendations met P-I-O structure; the absence of each component was $31.2 \%$ for population, $6 \%$ for intervention and $85.2 \%$ had no outcome. The item 15 of AGREE-II instrument reported results between 4 and 7 , scores of good quality.

Discussion Recommendations in CPG seem to be clear, but most of them don't contain the evaluated criteria for their report. External evaluation emphasises in clarity of recommendation, and there is no agreement with the percentages obtained according to P-I-O structure, which enhance its understanding. Implications It is advisable to standardise methodology for recommendations to include all components that reflect the answer to the research question.

\section{P343 SELLING OLD WINE IN NEW BOTTLES: WHY IT IS WORTHWHILE TO HAVE ANOTHER GUIDELINE DEVELOPMENT HANDBOOK?}

C Muche-Borowski, M Nothacker, I Kopp. AWMF Institute of Medical Knowledge Management, Marburg, Germany

\section{0:1136/bmjqs-2013-002293.264}

Background Since 1995, the Association of the Scientific Medical Societies in Germany (AWMF) maintains an open access, quality assured guideline register (www.awmf.org), currently containing 676 guidelines developed by 168 societies. While the societies are responsible for topic selection, development and content, the mission of AWMF is to promote, support and coordinate guideline development and to ensure the overall quality of the guideline register. To achieve this goal, AWMF established a new set of recommendations and rules.
Context Published manuals for guideline developers do not fully meet the requirements of our national guideline system. Our manual takes into account the - development of methodological strategies - international consensus on key criteria for "good guidelines" - target group including guideline novices and clinical experts wishing to be informed about methodological developments but to delegate project management and basic methodological work - informational need to include guidelines into the AWMF register - specific requirements of the German health care system (e.g. the patients' rights act)

Description of Best Practice Our manual consists of two parts. The first part includes recommendations and practical advice for guideline developers. The second part includes rules AWMF applies to judge inclusion into the register (e.g. addressing the management of conflict of interests).

Lessons for Guideline Developers, Adaptors, Implementers, and/ or Users Our guideline development handbook which will be updated continuously may serve as an example for methodological guidance that is based on a systematic review of the international literature as well as the identification of national requirements and experience.

\section{P348 PATIENT AND CONSUMER INVOLVEMENT IN GUIDELINE INTERPRETATION AND PATIENT TOOL DEVELOPMENT; A COMPARISON OF TWO FOCUS GROUPS AND UNDERSTANDING CULTURAL DIVERSITY}

${ }^{1} \mathrm{C}$ Davino-Ramaya, ${ }^{2} \mathrm{~K}$ Ramaya, ${ }^{1} \mathrm{H}$ Tucker. ${ }^{1}$ Kaiser Permanente (Northwest Permanente), Portland, USA; ${ }^{2}$ Pacific University, Forest Grove, USA

\section{0:1136/bmjqs-2013-002293.265}

Incorporating patient and consumer involvement in clinical practice guideline (CPG) activities has become a priority for health care organisations internationally. In diverse populations with potential healthcare disparities the development of culturally competent patient tools based on interpretation of preexisting clinical practice guidelines is also considered important practice for many organisations that adopt external guidelines. In our exploration of the role of consumer engagement in the development of CPG support tools and in addressing healthcare disparities we compare the results of two culturally different groups through the evaluation of pre and post surveys as well as in-person focus groups. Survey intent was to gauge awareness of the existence of CPGs and gauge interest in developing patient and consumer support tools. Results of one culturally diverse group are compared with a minority group. We analyse the perceptions and attitudes of high priority health care issues identified by both groups. Our findings underscore the opportunity for health care organisations with significantly different populations to address healthcare disparities in the development of patient and consumer CPG support tools. As an extension of our previous work on "collaborative engagement" our comparative results emphasise the need to appropriately address cultural, language and health literacy issues as well as addressing health disparities between populations. We focus on identifying barriers to access and treatment and discuss implication for practice as well as future directions.

\section{P352 GAME-IT (GAMES FOR IMPROVING TREATMENT- RECOMMENDATIONS)}

${ }^{1} \mathrm{~L}$ Brandt, ${ }^{2} \mathrm{~S}$ MCCallum, ${ }^{1} \mathrm{~A}$ Kristiansen, ${ }^{3} \mathrm{~T}$ Agoritsas, ${ }^{4} \mathrm{E}$ Akl, ${ }^{1} \mathrm{P}$ Vandvik, ${ }^{5} \mathrm{~V}$ Montori. ${ }^{1}$ Department of Medicine, Innlandet Hospital Trust, Gjøvik, Norway; ${ }^{2}$ Game 